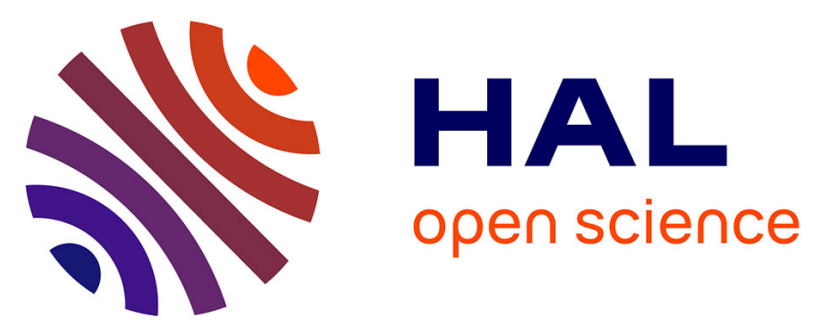

\title{
Flower strips adjacent to greenhouses help reduce pest populations and insecticide applications inside organic commercial greenhouses
}

Shu Li, Coline C Jaworski, Séverin Hatt, Fan Zhang, Nicolas Desneux, Su Wang

\section{To cite this version:}

Shu Li, Coline C Jaworski, Séverin Hatt, Fan Zhang, Nicolas Desneux, et al.. Flower strips adjacent to greenhouses help reduce pest populations and insecticide applications inside organic commercial greenhouses. Journal of Pest Science, 2021, 94 (3), pp.679-689. 10.1007/s10340-020-01285-9 . hal03278038

\section{HAL Id: hal-03278038 \\ https://hal.inrae.fr/hal-03278038}

Submitted on 5 Jul 2021

HAL is a multi-disciplinary open access archive for the deposit and dissemination of scientific research documents, whether they are published or not. The documents may come from teaching and research institutions in France or abroad, or from public or private research centers.
L'archive ouverte pluridisciplinaire HAL, est destinée au dépôt et à la diffusion de documents scientifiques de niveau recherche, publiés ou non, émanant des établissements d'enseignement et de recherche français ou étrangers, des laboratoires publics ou privés.

\section{(c)(1)}

Distributed under a Creative Commons Attribution| 4.0 International License 


\title{
Flower strips adjacent to greenhouses help reduce pest populations and insecticide applications inside organic commercial greenhouses
}

\author{
Shu $\mathrm{Li}^{1} \cdot$ Coline C. Jaworski ${ }^{2}$ - Séverin Hatt ${ }^{3} \cdot$ Fan Zhang $^{1} \cdot$ Nicolas Desneux $^{4} \cdot$ Su Wang $^{1}$
}

Received: 30 April 2020 / Revised: 14 September 2020 / Accepted: 21 September 2020 / Published online: 30 September 2020

(c) Springer-Verlag GmbH Germany, part of Springer Nature 2020

\begin{abstract}
Flower strips can play an important role in agro-ecosystems by supporting populations of pests' natural enemies, thereby enhancing biological control. However, few studies have considered enhancing habitat for natural enemies around greenhouses. We conducted a two-year field experiment to (i) identify potential flowering species enhancing natural enemy populations but not pest populations; and (ii) evaluate how the presence of flower strips adjacent to greenhouses helped reduce pest abundance and insecticide use by attracting natural enemies inside greenhouses. We tested six flowering species in monofloral plots placed in flower strips adjacent to greenhouses and measured pest and predator abundance in monofloral plots but also on eggplants as well as eggplant yield and insecticide use inside greenhouses. All flowering species attracted more pests and predators than strips of naturally occurring weeds. Cosmos bipinnatus and Borago officinalis hosted high predator abundance and low pest abundance. Conversely, Tagetes erecta and Verbena $x$ hybrida hosted intermediate predator abundance but high pest abundance, and Cirsium setosum and Centaurea cyanus hosted lower predator and pest abundances. Overall, both predator and pest numbers were higher at high flower density. Pest abundance was reduced by $43 \%$ in greenhouses adjacent to flower strips compared with control greenhouses, while predator numbers were 20 times higher, and insecticide use was reduced by $34 \%$, but yields remained unchanged. Flower strips around greenhouses are therefore a promising, economically viable strategy to enhance pest control and to reduce insecticide use, and mixtures of flowering species in flower strips should be further tested to enhance the diversity of the predator community.
\end{abstract}

Keywords Conservation biological control · Habitat enhancement · Companion plant · Insectary plant · Natural enemy · Pesticide $\cdot$ Predator $\cdot$ Trap crop

Communicated by M. Traugott.

Shu Li and Coline C. Jaworski equally contributed to this work.

Electronic supplementary material The online version of this article (https://doi.org/10.1007/s10340-020-01285-9) contains supplementary material, which is available to authorized users.

Su Wang

anthocoridae@163.com

1 Institute of Plant and Environment Protection, Beijing Academy of Agriculture and Forestry Science, Beijing 100097, China

2 Department of Zoology, University of Oxford, Oxford OX1 3PS, UK

3 Laboratory of Forest Ecology, Faculty of Agriculture, Kyoto University, Kyoto 606-8502, Japan

4 UMR ISA, University Côte D’Azur, INRAE, CNRS, 06000 Nice, France

\section{Key message}

- Habitat enhancement for pest natural enemies to improve pest control is overlooked in greenhouse farms. We tested the impact of flower strips adjacent to greenhouses, which helped reduce pest populations, by attracting predatory natural enemies inside greenhouses.

- Consequently, insecticide applications were reduced, but yields remained unaffected.

- Tested flowering species vary in their attractiveness to natural enemies versus pest species; hence, the choice and the mixture of flowering species established in flower strips should be optimized. 


\section{Introduction}

Reducing pesticide use in agro-ecosystems is central to mitigate their negative impacts on invertebrate communities, including biodiversity loss, the disruption of ecosystem services and the overall destabilization of ecosystems (Desneux et al. 2007; Geiger et al. 2010; Lu et al. 2012; Mohammed et al. 2018; Pretty 2018). Integrated pest management provides a framework to optimize pesticide use and sustain food production while limiting adverse effects to biodiversity and the environment (Kogan 1998). As an alternative to insecticides, conservation biological control aims at enhancing pest control by natural enemies locally present in the environment (Gurr et al. 2017; Michaud 2018), and should therefore be a major component of integrated pest management (Orr 2009). There is consensual evidence showing that the simplification of agroecosystems has led to a decrease in pest control (Rusch et al. 2016). Mitigation strategies aiming at enhancing habitats for natural enemies within agro-ecosystems have received considerable attention lately (Tscharntke et al. 2007; Lundgren et al. 2009; Holland et al. 2016; Pretty 2018; González-Chang et al. 2019; Snyder 2019; Thomine et al. 2020).

Enhancing floral resources in agro-ecosystems via the establishment of flower strips within and around crop fields has been shown to promote populations of natural enemies and the regulation of pest populations in neighboring fields (Pfiffner et al. 2009; Balzan et al. 2016; Tschumi et al. 2016a, b; Hatt et al. 2019a; Snyder 2019). This is because flowers can provide resources to natural enemies, including complementary food resources such as pollen and nectar, resources for alternative hosts or prey, or shelter or reproductive sites (Baggen et al. 1999; Bugg and Waddington 1994; Lu et al. 2014). In addition, flowers may help attract and retain natural enemies in suboptimal cropped environments, where frequent disturbance prevents efficient settlement of natural enemy populations (Gurr et al. 2017; Hatt et al. 2017a; Perović et al. 2018; Jaworski et al. 2019). For instance, Gurr et al. (2016) reported that local nectar-producing plants grown around rice fields led to an increase in the abundance of predators and parasitoids, and a decrease in the abundance of two major pests in rice, the planthopper species Nilaparvata lugens Stål (Lepidoptera: Delphacidae) and Sogatella furcifera Horváth (Lepidoptera: Delphacidae). This in turn allowed a reduction in insecticide applications by $70 \%$ and resulted in an increase in rice yields by $5 \%$ and in economic benefits by $7.6 \%$.

While flowers are expected to attract and support natural enemies (Balzan and Wäckers 2013; Campbell et al. 2017), they may also attract and support pest populations that could be detrimental to adjacent crops. Indeed, pest arthropods could also benefit from nectar and pollen resources, or use flowering plants as secondary hosts (Dixon and Kundu 1994; Karin et al. 2009; Winkler et al. 2009). Still, attractive flowers could be used as trap plants if they prevent pests from colonizing crops, i.e., if they are highly attractive to pests but poorly suitable hosts in terms of development and fecundity (Sarkar et al. 2018). Therefore, to efficiently use flowers in agro-ecosystems in conservation biological control programs, an assessment of their effects on both natural enemies and pests is required (Fiedler and Landis 2007).

So far, floral enhancement to support natural enemies in agro-ecosystems has been mainly investigated and applied to open crop fields and orchards (Haro et al. 2018; Hatt et al. 2017a; Jaworski et al. 2019), but rarely to greenhouses (but see e.g., Rodríguez et al. 2017), and is barely tested in China, although it has received more attention lately (Dai et al. 2015; Gurr et al. 2016). Although greenhouses may be perceived as more isolated from the surrounding environment than open crop fields, the outdoor environment is a major source of pests and natural enemies inside greenhouses. Greenhouses, notably in China (Yang et al. 2014), are often unheated plastic structures with roll-up sides providing ventilation while allowing movements of pests and natural enemies (Gabarra et al. 2004). Hence, implementing and managing flower strips around greenhouses could potentially enhance conservation biological control of insect pests, provided a choice of flowering species tailored to targeted natural enemies (Hatt et al. 2020; Tschumi et al. 2016a).

Flowering species managed in flower strips greatly vary across studies; they are often indigenous species tailored to support local targeted natural enemies' populations, e.g., aphidophagous species or Lepidoptera natural enemies (Pfiffner et al. 2009; Wäckers and van Rijin 2012; Tschumi et al. 2016a), by attracting them to flower strips and the neighboring environment, and to reward them by providing accessible nectar and pollen resources (Wäckers and van Rijin 2012; Damien et al. 2017; Hatt et al. 2019b; Snyder 2019). Commonly grown flowering species in China include borage (Borago officinalis L., Boraginales: Boraginaceae), cornflower (Centaurea cyanus L., Asterales: Asteraceae), cosmos (Cosmos bipinnatus Cav., Asterales: Asteraceae), marigold (Tagetes erecta L., Asterales: Astearaceae) and verbena (Verbena x hybrida Voss., Lamiales: Verbenaceae). They are fast growing widespread species in China and tolerate sunny environments (Ji 2007; Zhang 2012; Gao and Wu 2017). Borage, cornflower and cosmos have been shown to attract and increase the longevity of hemipteran predatory bugs, hoverflies, lacewings and parasitoid wasps, notably by providing nectar (Sadeghi 2008; Hogg et al. 2011; Wäckers and van Rijn 2012; Carrié et al. 2012; Sarkar et al. 2018). Marigold has been tested as a trap crop (i.e., a companion 
plant attracting pests) targeting Helicoverpa armigera Hübner (Lepidoptera: Noctuidae) in tomato crops and thrips in roses (Bueno et al. 2009; Sarkar et al. 2018). Finally, verbena has been used as a banker plant (hosting alternative prey for natural enemies; Nakano et al. 2016).

In the present study, we aimed to test the potential of flower strips adjacent to greenhouse to improve pest regulation on eggplant crops in organically grown greenhouses. Major pests of eggplants are aphids and thrips, which are preyed upon by a diversity of generalist predators, including ladybeetles, lacewings, hoverflies, flower bugs and spiders (Cui et al. 2012; Yang et al. 2014). A 2-year preliminary survey showed that the main pest species in eggplants locally are the aphids Myzus persicae Sulzer (Hemiptera: Aphididae) and Aphis gossypii Glover (Hemiptera: Aphididae) and thrips Frankliniella occidentalis Pergande (Thysanoptera: Thripidae) at a very low abundance $(<1 \%$ of total pest numbers), while other pest species are rare (authors' personal observation). In the present study, we asked: (i) How do the flowering species differ in their potential to support populations of natural enemies, but not pest populations?; and (ii) How does the implementation of flower strips adjacent to greenhouses affect the abundance of pests and natural enemies inside greenhouses, and how does it affect the need for insecticide applications as well as crop yields? We investigated these questions in a 2-year experiment including six greenhouses of eggplant crops in an organic greenhouse commercial farm in northern China.

\section{Material and methods}

The study was conducted at Noah Organic Farm (N40 $09^{\prime}$, E116 99') in Pinggu County of Beijing (China) in 2014 and 2015. The organic management of the farm is certified to follow the European, American and Japanese requirements for organic farming. The farm is located in a village about $50 \mathrm{~km}$ away from heavily urbanized areas and is surrounded by a mosaic landscape composed of wheat open fields, grasslands and mixed woodlands. Beijing has a typical temperate and monsoonal climate with four distinct seasons. The average temperature on the farm during the experimental time was $25.6^{\circ} \mathrm{C}$ and $25.5^{\circ} \mathrm{C}$ in 2014 and 2015 , respectively (Table S1), with 555 and $583 \mathrm{~mm}$ average rainfall in 2014 and 2015 , respectively.

\section{Flower strips}

Six flowering species were chosen as candidates based on their wide distribution and characteristics (reviewed above): borage B. officinalis, cornflower C. cyanus, garden cosmos $C$. bipinnatus, marigold $T$. erecta and verbena $V$. hybrida. All seeds were obtained from the Institute of Botany,
Chinese Academy of Science. The thistle Cirsium setosum (Asterales: Asteraceae), a perennial and locally dominant weed around greenhouses, was also included in the survey. Seeds of the five other species were started in plastic trays on April 8 both years and individually transplanted at a stage of three to four fully developed true leaves in situ on May 2, 2014, and May 3, 2015. Six monofloral plots per flower strip were established in alleys between greenhouses (Fig. 1). They were placed in a random sequence in the strip and replicated on three alleys, so that monitored greenhouses adjacent to a flower strip were at least two greenhouses apart. Plant density was approximately 80 plants per plot. Bare soil was maintained between each plot, and weeds were manually removed regularly within plots. In the thistle plots, only naturally occurring thistle plants were maintained at a density similar to other monofloral plots. Weedy strips adjacent to control greenhouses and on the other side of greenhouses adjacent to a flower strips were mown once a month and colonized by naturally occurring plant species, mostly C. setosum, Amaranthus viridis L. (Caryophyllales: Amaranthaceae) and Plantago asiatica L. (Lamiales: Plantaginaceae). The environment surrounding greenhouses was homogeneous; hence, this is unlikely that it contributed as a source of pests or predators differentially across control or flower strip greenhouses.
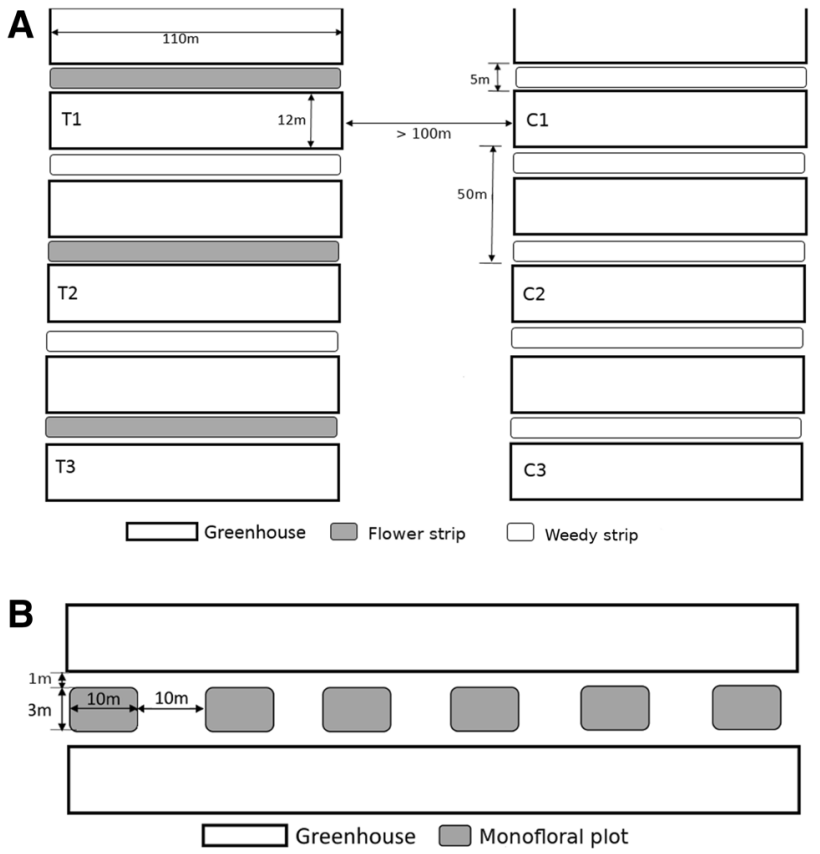

Fig. 1 a Position of flower strips respective to surveyed greenhouses (T: greenhouses adjacent to a flower strip; C: control greenhouses) in the commercial farm. A similar pattern of selected greenhouses and flower strips was used both years. b Position of the monofloral plots in each flower strip 
Arthropods in all monofloral plots were monitored every week from May 21 to September 3, 2014 and 2015 (16 times each year), between 9 and $11 \mathrm{am}$. On each sampling date, the populations of natural enemies (composed of mostly mobile, predatory arthropods) and of pests (mostly thrips and non-winged aphids, hence not mobile) were monitored via two different methods. Predators were caught by sweep netting along a 3-m-long transect in the middle of each monofloral plot for $2 \mathrm{~min}$. They were later counted, identified to the family and species level when possible, and grouped into five functional groups: ladybeetles, lacewings, flower bugs, hoverflies and spiders. After sweep netting, insect pests were observed and counted on five groups of three plants randomly selected throughout each monofloral plot. When the species could not be identified on the plant, individual specimens were collected and later identified to the species when possible using a binocular. Whole plants were fully observed, including leaves, stems and flowers. This resulted in a number of thrips and of aphids per 15 plants per sampling date. In addition, the density of flowers was estimated visually at each sampling date and expressed as the percentage of the total number of open flowers in a plot relative to the maximum number of open flowers measured at flowering peak time: $0-9 \%, 10-49 \%$ or $50-100 \%$ (Fig. 2). This way, the relative abundance of flowers through time could be easily compared across flowering species. As a control of the natural arthropod diversity in the environment surrounding greenhouses, we also assessed the abundance and diversity of predators and pest individuals in naturally weedy strips adjacent to control greenhouses, in three plots per year and similarly to monofloral plots. Flower density was always low in the weedy plots $(<10 \%$ of flower density in monofloral plots).

\section{Organic eggplant production and pest regulation in greenhouses}

Eggplants (Solanum melongena L., Solanaceae 'Jingqie No.13,' Jingyan Yinong, Beijing Seed Sci-Tech Co., Ltd.) were sown in plastic trays in plastic greenhouses on April 1, 2014, and April 3, 2015. Plants were then planted in 138 rows of 24 plants each (intra-row space $40 \mathrm{~cm}$; inter-row space $80 \mathrm{~cm}$ ) inside greenhouses on May 15, 2014, and May 17,2015 . Three greenhouses were adjacent to one flower strip each and distant by at least $50 \mathrm{~m}$ from each other; and three other greenhouses were chosen as control replicates and were at least $100 \mathrm{~m}$ away from the greenhouses with flower strips (Fig. 1). The alleys without flower strips (the opposite side of the flower strip, and the two sides of the control greenhouses) were left with a naturally occurring weed community. Greenhouses were ventilated daily from 10 am to $3 \mathrm{pm}$ during eggplant growing season to maintain average temperature below $30^{\circ} \mathrm{C}$, via manually activated, lateral roll-up sides providing openings from 3 to $4 \mathrm{~m}$ above the ground along each long side of the greenhouse.

Natural enemies and pest individuals occurring on eggplants were counted at 10-day intervals from June 27 to August 16, 2014, and from June 26 to August 15, 2015 (six times each year). At each sampling date, five groups of 10 plants were randomly selected throughout the greenhouse, and at least five plants away from edges. All predators and pest individuals observed on each eggplant (including all leaves, stems and flowers) were counted and summed to

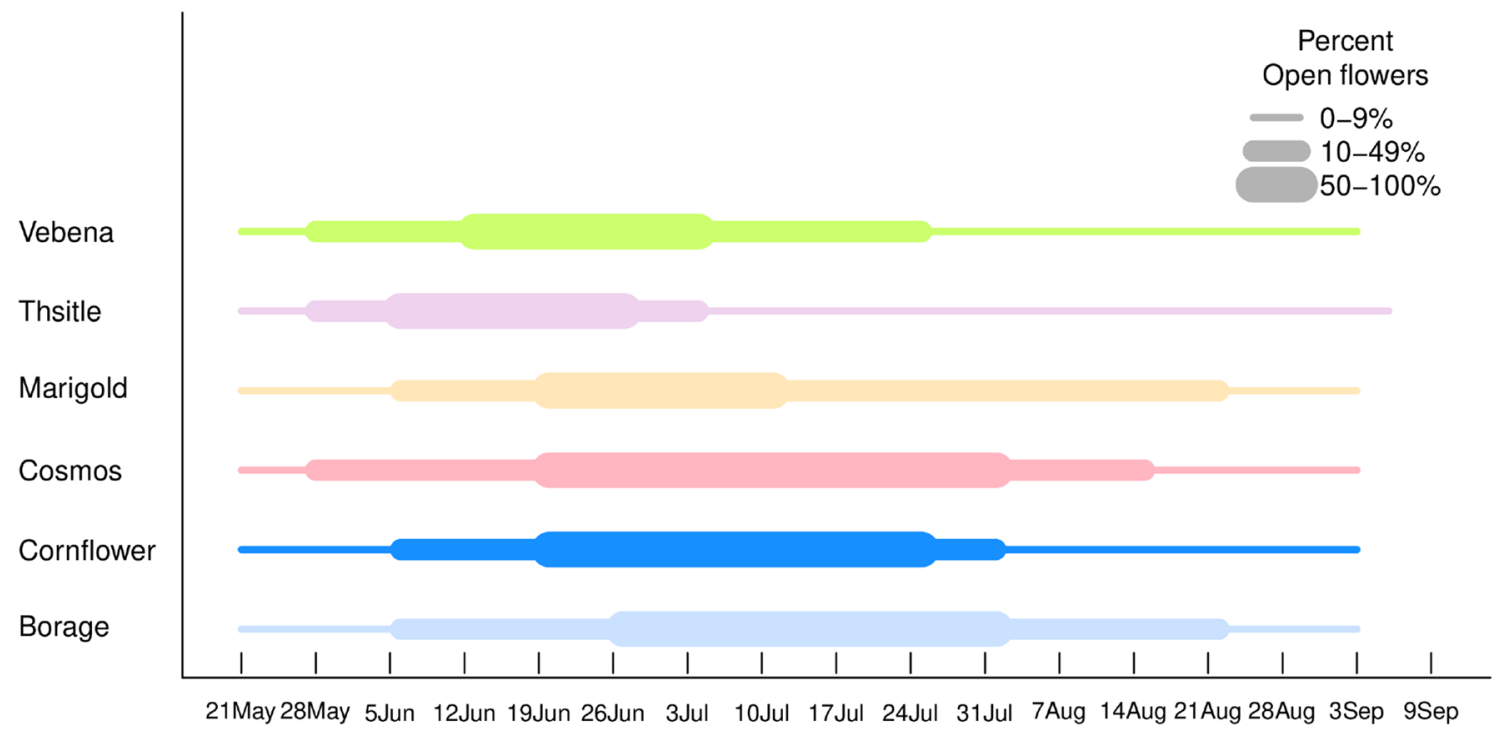

Fig. 2 Flowering phenology and percentage of open flowers (relative to the maximum number of open flowers at flowering peak time) in 2014 and 2015 for the six flowering species studied 
obtain a total number of predators and a total number of pest individuals per 50 plants and per sampling date.

In our experiment in all greenhouses, biological insecticide $(0.5 \%$ Vetrine alcoholic solution, Tianyisheng brand, China) was applied two days after arthropod sampling and every ten days, from June 27 to August 16, 2014, and from June 26 to August 15, 2015. Following commercial practices, heavily infested plants ( $>30$ aphids per plant) were sprayed with a higher volume of insecticide than plants with low pest numbers. The total volume (in $\mathrm{mL}$ ) sprayed per greenhouse and per sampling date was recorded each time. Crop production was harvested around seven times for each plant in such commercial greenhouses. Data from one harvest only were collected for practical reasons (August 30, 2014, and August 29, 2015): Fruits from 50 eggplants randomly chosen in each greenhouse were weighed to evaluate the vegetable production.

\section{Statistical analyses}

All analyses were performed with R version 3.6.1 (R Core Team 2019). First, we investigated the effect of the flowering species in each monofloral plot (borage, cornflower, cosmos, marigold, verbena and thistle) on the total number of pests per 15 plants and on the total number of predators along a 3-m transect, using separate linear mixed-effects models (LMMs, function 'Imer,' R package 'Ime4,' Bates et al. 2015). Data were $\log (x+1)$-transformed to account for data overdispersion. The identity of the flowering species, the abundance of flowers (Fig. 2) as well as the interaction between the two were tested as fixed effects, with the year as co-variable. The relative abundance of flowers was implemented as a continuous variable, extrapolated based on a Gaussian fit of the percent open flowers. The monofloral plot replicate was used as a random effect to account for repeated measures through time in each plot. The significance of effects was estimated through a type II comparison of models, starting with the second-order interaction between fixed effects and based on log-likelihood ratio tests. We verified a posteriori for heteroscedasticity and overdispersion of residuals from the best model (functions 'ks.test' and 'testDispersion'; R package 'DHARMA'; Hartig 2019). Finally, we compared the total number of pest individuals and the number of aphids per 15 plants through time and the number of predators along a 3-m transect through time in monofloral plots versus weedy plots by performing three Wilcoxon-signed rank tests, with the nature of plot (monofloral versus weedy) as factor.

Second, we analyzed the differences in the composition of arthropod communities in each monofloral plot and across different flower densities by performing a redundancy analysis (function 'rda,' R package 'vegan,' Oksanen et al. 2019) on the community data matrix (numbers of ladybeetles, lacewings, flower bugs, hoverflies and spiders along a 3-m transect and numbers of aphids and thrips per 15 plant at each sampling date). Similar to the analysis of the total numbers of pests and predators above, the fixed effects were the flowering species and the flower density (this time used as a factor with three levels: $0-9 \%, 10-49 \%$ and $50-100 \%$ open flowers) as fixed effects, as well as the second-order interaction between the two, and the year as co-variable. We performed a second test comparing the composition of arthropod communities in monofloral versus weedy plots (fixed factor: monofloral vs. weedy; co-factor: year). For both tests, the significance of fixed effects was estimated through a type II model comparison based on a Fisher test. Data were visualized with a two-dimensional principal component analysis and each year separately.

To evaluate the effect of the presence of a flower strip adjacent to the greenhouse on pest control on eggplants inside the greenhouse, the number of pests and of predators per 50 plants were compared between treatments using separate generalized linear mixed-effects models (function 'glmer,' R package 'Ime4,' Bates et al. 2015). A negative binomial distribution was used to account for data overdispersion. The treatment (presence/absence of an adjacent flower strip) was implemented as a fixed effect, and the year (2014 vs. 2015) as a co-variable, while the greenhouse number was implemented as a random effect to account for repeated measures through time in each greenhouse. Assessing the significance of the treatment effect as well as post hoc model validation were performed following the same method as for arthropod numbers in monofloral plots above. The effect of the presence/absence of a flower strip adjacent to the greenhouse on yields and insecticide volumes sprayed inside the greenhouse was analyzed in the same way as for arthropod numbers, except that an LMM was used instead.

\section{Results}

\section{Effect of flowering species on the abundance and diversity of predators and pests in monofloral plots}

Totally, 4444 individuals of predators (ladybirds, lacewings, hoverflies, flower bugs and spiders), 4327 aphids and 8793 thrips were collected over the two study years (Table S2). Both predators and pests were more abundant in 2015 than in 2014. Lacewings and flower bugs were the most abundant predators accounting for more than $70 \%$ of all predator individuals. Frankliniella occidentalis was the most abundant pest species, representing $60 \%$ of all pest individuals collected in 2014 and 2015. Myzus persicae and A. gossypii were the most abundant aphid species. 
Overall, total numbers of predators along a 3-m transect within each monofloral plot were higher in 2015 than 2014 and greatly varied across plots from different flowering species (Fig. 3). The interaction between the flowering species and the flower density had an effect on predator numbers $\left(d f=5, \chi^{2}=80.0, P<0.001\right)$. The mean number $( \pm S E)$ of predators along a 3-m transect was higher in cosmos and borage plots ( $14 \pm 2$ and $13 \pm 2$, respectively; Table S3) than marigold and cornflower plots ( $8 \pm 1$ and $7 \pm 1$, respectively), while verbena and thistle plots attracted low numbers $(4 \pm 1$ and $2 \pm 1$, respectively). Predators positively and strongly responded to higher flower densities of borage and cosmos, but their response to cornflower density was moderate, and they did not respond to the density of marigold, thistle and verbena (Table S3). Finally, the number of pest individuals per 15 plants was eight times higher in average in monofloral plots than in weedy strips $(23 \pm 1$ and $3 \pm 1$, respectively; $W=241,709, P=0.0051)$, but the number of aphids - the pest species of concern for eggplant production-was only four times higher in average in monofloral plots compared with weedy strips $(8 \pm 1$ and $2 \pm 1$, respectively; $W=236,067, P=0.0062$ ).

Total numbers of pest individuals per 15 plants in each monofloral were not different between years, but they were affected by the flowering species $\left(d f=5, \chi^{2}=64.3\right.$, $P<0.001$; Fig. 3). They also responded positively to the flowering density $\left(d f=1, \chi^{2}=33.5, P<0.001\right)$, but not to the interaction between the flowering density and the flowering species (Table S3). Marigold plots supported the highest number of pest individuals per 15 plants (mean \pm SE: $54 \pm 5$ ) and twice as many as in verbena plots $(28 \pm 3)$ or cosmos plots $(21 \pm 3)$, while borage, cornflower and thistle plots had lower numbers $(15 \pm 2 ; 12 \pm 1$; and $7 \pm 2$, respectively; Fig. 3; Table S3). Finally, the number of predators along a 3-m transect was four times higher in monofloral plots compared with weedy strips $(8 \pm 1$ and $2 \pm 1$, respectively; $W=236,871, P=0.0055)$.

We then investigated how the flowering species and the flower density in monofloral plots affected the composition of the arthropod community (Fig. 4). The interaction between the flowering species and the flower density significantly affected the composition of the arthropod community $\left(F_{10,557}=8.16, P=0.001\right)$. Both years, communities across monofloral plots of different flowering species were more dissimilar at high flower densities (Fig. 4) and very similar at low flower density, except for verbena and thistle plots in which flower density played little in community composition due to low arthropod numbers. High flower density plots of borage and cosmos were dominated by lacewings and hoverflies both years, and high flower density plots of cornflower and marigold were dominated by ladybeetles and thrips in 2014 and thrips but not ladybeetles in 2015. Flower bugs were relatively more abundant in high flower density plots independent of the flowering species both years, while this was true for spiders in 2014 only. In 2015, spiders were relatively more abundant in high-density plots of borage. Aphids were relatively more abundant in thistle plots both years and in borage plots in 2014, and they were relatively less abundant in cosmos and cornflower plots both years. Interestingly, thrips and aphid abundances were inversely correlated, while ladybeetle abundance was correlated with that of thrips in 2014 and that of aphids in 2015 . Weedy strips differed from monofloral plots in the composition of the arthropod community $\left(F_{1,1329}=38.11, P=0.001\right)$. They were dominated by ladybeetles and spiders and thrips in 2014 and aphids in 2015 (Fig. 4).

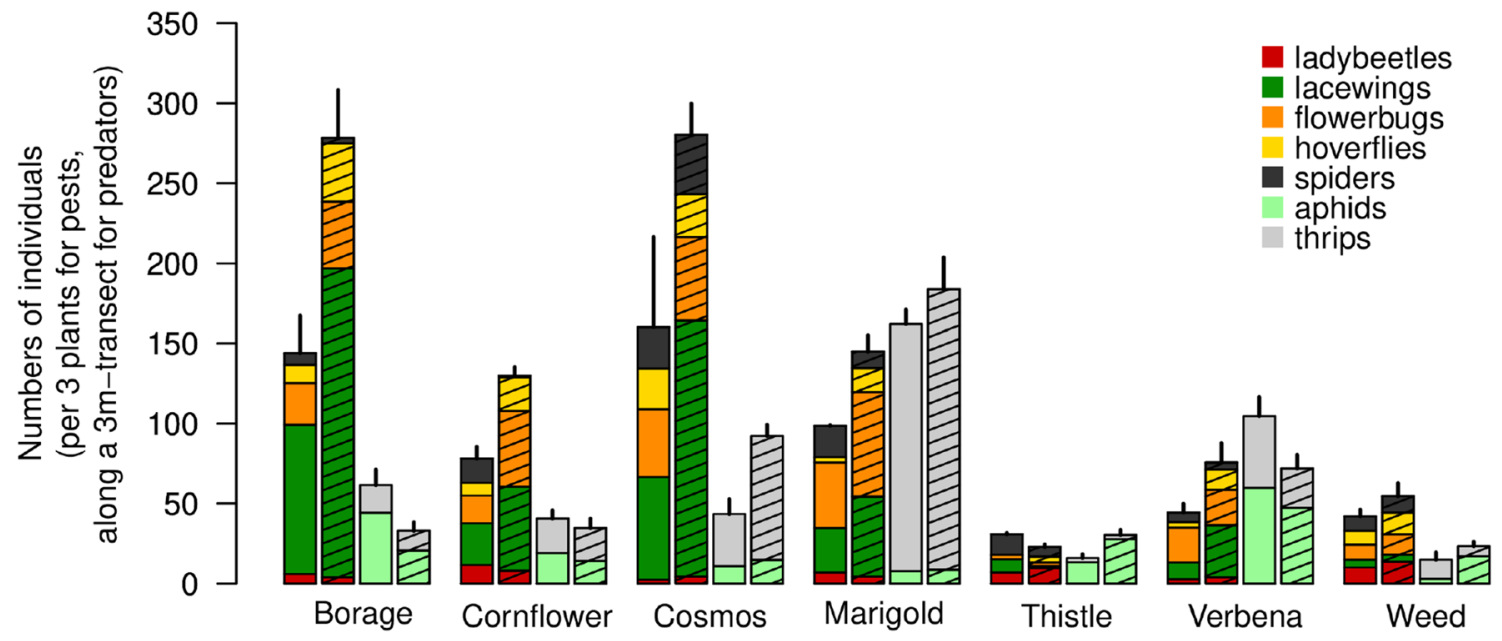

Fig. 3 Total numbers of predators along a 3-m transect and of pest individuals per three plants in monofloral plots summed throughout the season in the six types of monofloral and weedy plots. Mean \pm SE; $N=3$ replicates. Light bars: 2014; hatched bars: 2015 

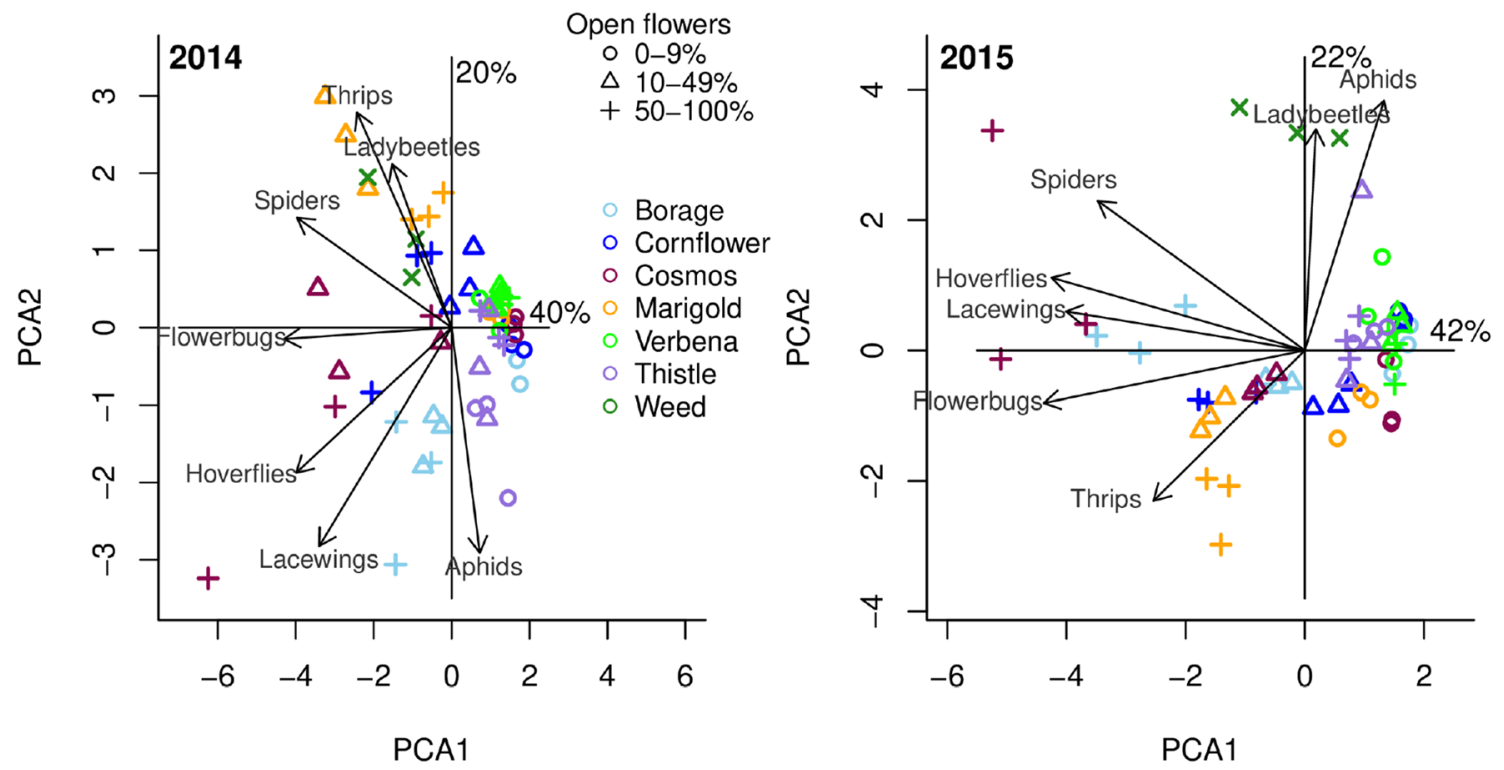

Fig. 4 Principal component analysis of arthropod communities in monofloral and weedy plots in 2014 (left) and 2015 (right), on summed numbers of pests and predators in each functional group in monofloral plots at sampling dates with similar percent open flowers

\section{Effect of the presence of flower strips on pest control and eggplant production inside greenhouses}

The number of pest individuals was higher in control greenhouses compared with greenhouses adjacent to a flower strip both years and peaked in late July. Natural enemies found inside greenhouses were predators only, and the same species as found in flower strips (mainly $O$. sauteri, H. axyridis and C. pallens). Predator numbers peaked in early August and were higher in greenhouses adjacent to flower strips. The number of pests per 50 plants was reduced by $43 \%$ in average in greenhouses adjacent to flower strips $(215 \pm 25)$ compared with control greenhouses $(373 \pm 37)$, while the number of predators per 50 plants was more than 20 times higher in average in greenhouses adjacent to flower strips $(57.9 \pm 5.6)$ compared with control greenhouses $(2.8 \pm 0.6$; Fig. 5). The presence/absence of a flower strip adjacent to the greenhouse significantly affected pest numbers $(d f=1$, $\left.\chi^{2}=8.99, P=0.0027\right)$, as well as predator numbers $(d f=1$, $\left.\chi^{2}=37.89, P<0.001\right)$.

The presence/absence of a flower strip did not affect yields $\left(d f=1 ; \chi^{2}=2.82 ; P=0.093\right)$, and the fruit harvest per plant was $464 \pm 3 \mathrm{~g}$ (Fig. 6). The volume of insecticide sprayed in each greenhouse was reduced by $34 \%$ in average

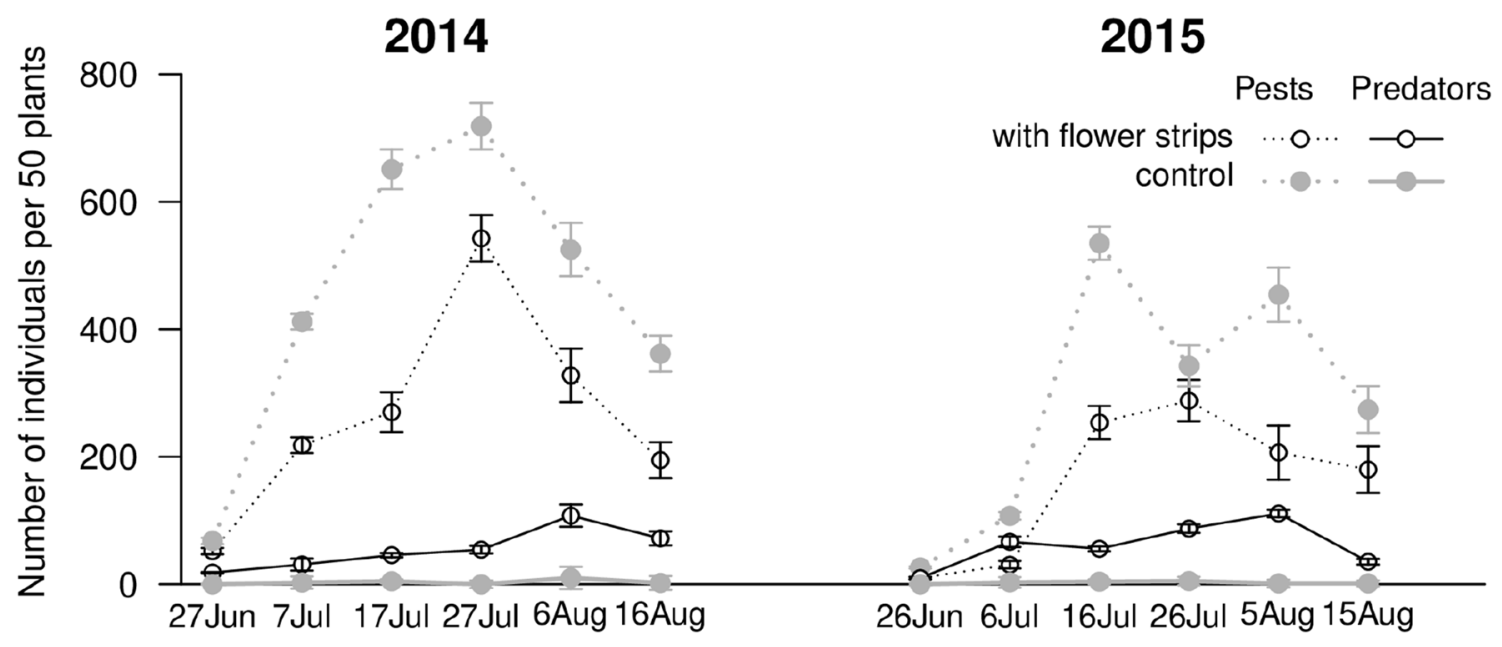

Fig. 5 Dynamics of pest and predator populations on eggplants in 2014 (left) and 2015 (right), in greenhouses adjacent to flower strips (black) and control greenhouses (gray; mean $\pm \mathrm{SE} ; N=3$ replicates) 


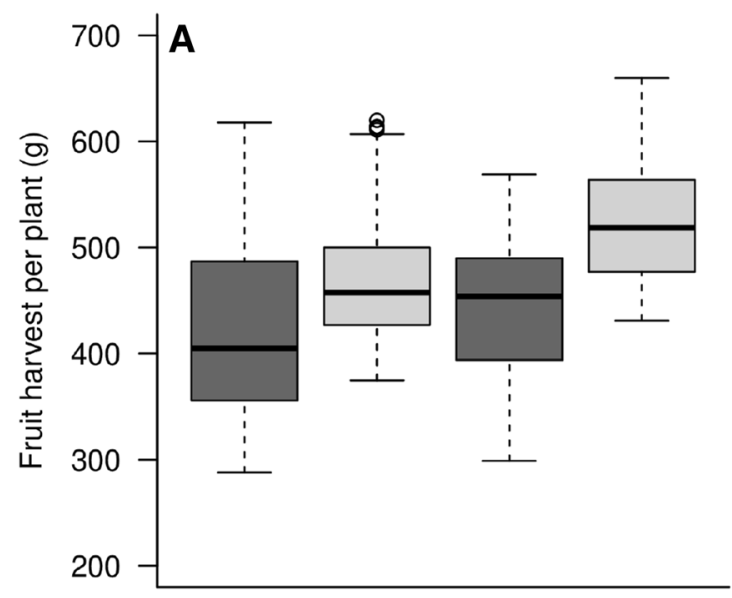

2014

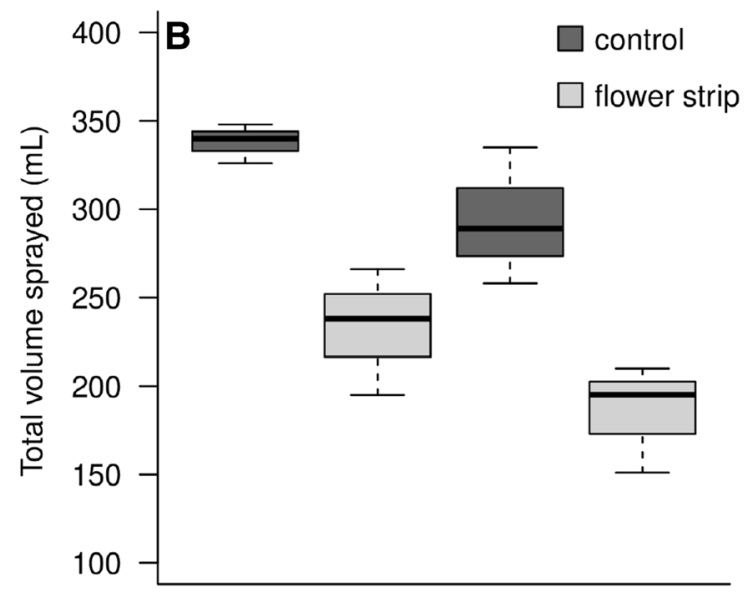

2014

2015

Fig. 6 Yields (fruit harvest per plant; A) and total volume of insecticide sprayed per greenhouse (B). Mean, 1st and 3rd quantiles and 95\% confidence interval

in greenhouses adjacent to flower strips $(209 \pm 16 \mathrm{~mL})$ compared with control greenhouses $(316 \pm 14 \mathrm{~mL}$; Fig. 6). The presence/absence of a flower strip adjacent to the greenhouse affected the volume sprayed $\left(d f=1 ; \chi^{2}=11.01, P<0.001\right)$.

\section{Discussion}

In the present study, we showed that the implementation of flower strips adjacent to greenhouses helped decrease pest pressure on vegetable crops inside greenhouses, with a significant increase in predator numbers inside greenhouses. Farmers adjusted insecticide applications to pest pressure, and the presence of flower strips therefore resulted in a decrease in insecticide use with no impact on crop yields. We also showed that the flowering species tested differed in their capacity to support populations of predators and pests, and these findings could be used to enhance the design of flower mixtures in future flower strips. This is therefore a promising strategy which could be developed in integrated pest management programs (Tscharntke et al. 2007; Orr 2009). The implementation of perennial flower strips would require initial investment and thereafter minor management (Tschumi et al. 2016b). Meanwhile, reduction in insecticide use, but also increase in crop price based on environmentally friendly practices would likely make this strategy economically viable. We estimated a net benefit around 14,700 RMB per greenhouse (see Supplementary Materials-Cost analysis).

In our experiment, the amount of insecticides used was adjusted to pest pressure and hence was lower in greenhouses with lower pest densities. This resulted in lower amounts of insecticide in greenhouses adjacent to a flower strip compared with control greenhouses, and hence a decrease in detrimental effects to predators. This may partially explain higher predator populations in control greenhouses (Geiger et al. 2010; Hatt et al. 2017a). However, since insecticide applications were adjusted to pest pressure, it is reasonable to conclude that predator populations inside greenhouses were mostly enhanced by the presence of flower strips, and this resulted in reduced pest populations prior to insecticide application. Also, our study brings a realistic experimental test of the application of flower strips to enhance pest control in a commercial greenhouse farm, where commercial practices were used. It is unlikely that insecticide applications may be completely avoided by the implementation of flower strips due to commercial requirements for harvest quality and quantity.

The six flowering species surveyed in flower strips showed contrasted capacities to support predator versus pest populations. The most promising species sustaining high predator populations were the $\operatorname{cosmos} C$. bipinnatus and the borage $B$. officinalis (Fig. 3). These flowering species were preferred by hoverflies, flower bugs and lacewings (Fig. 4). Contrasted effects of cosmos on predators were previously reported: Cosmos sulphureus Cav. (Asterales: Asteraceae) was found less attractive to hoverflies when tested against sweet alyssum (Lobularia maritima L., Brassicales: Brassicaceae) and mustard (Brassica juncea L., Brassicales: Brassicaceae), possibly because of a later flowering peak relative to life history of hoverflies than $C$. bipinnatus (Hogg et al. 2011; Gontijo et al. 2013). Also, van Rijn and Wäckers (2016) showed that the corolla of C. bipinnatus was the deepest among 32 other flowering plants, suggesting that hoverflies such as Episyrphus balteatus De Geer (Diptera: Syrphidae) cannot access nectar of this flower, and 
explaining why hoverfly longevity was not increased when they were exposed to it. However, Sadeghi (2008) reported opposite observations of hoverflies, including E. balteatus and Sphaerophoria scripta L. (Diptera: Syrphidae), often visiting C. bipinnatus in fields. As for lacewings, Wäckers \& Van Rijn (2012) indicated that Chrysoperla carnea Stephens (Neuroptera: Chrysopidae) can feed on pollen of C. bipinnata flowers, which slightly increased their longevity. Wäckers and Van Rijn (2012) showed that hoverflies and lacewings can live longer when they feed on B. officinalis, while Hogg et al. (2011) reported the presence of Anthocoridae in plots sown with B. officinalis. However, B. officinalis was the most attractive flowering species to aphids along with verbena (Fig. 4). If preferred to neighboring crop plants by aphids, borage could still be used as a trap plant (Parolin et al. 2012; Sarkar et al. 2018). In contrast, verbena would be of little interest as relatively unattractive to predators, as also shown in previous studies (Fiedler and Landis 2007).

Cornflower (C. cyanus) attracted a lower total number of predators compared with borage and cosmos (Fig. 3). It was especially attractive to flower bugs and ladybeetles, possibly due to the provision of extra-floral nectar which may be used by flower bugs and ladybeetles as an alternative food resource (Berkvens et al. 2010; Carrié et al. 2012; Wäckers and van Rijn 2012). Marigold (T. erecta) supported very high numbers of thrips and was also attractive to flower bugs, which may have been foraging on thrips (Wang et al. 2014; Bonte et al. 2015). Similarly to borage with aphids, marigold could be used as a trap plant if thrips are more attracted to and perform less well on marigold than neighboring crop plants. Thrips numbers were low inside all greenhouses (with or without flower strips); hence, this is likely that they would not have colonized crop plants from flower strips. In addition, thrips are not causing a strong pest pressure, and aphids should be the primary target for conservation biological control in greenhouse-grown eggplants; hence, flower strips should be tailored to aphids' natural enemies in this context. Finally, thistle (C. setosum) hosted low populations of predators and pests; thistles are known to be attractive mostly to florivores and pollinators (Theis 2007). The low attractiveness of thistle and verbena might also be due to an earlier flowering phenology compared with other studied species (Fig. 2).

Besides providing accessible resources and attracting predators, the flowering phenology of species used in flower strips is a key component in tailoring efficient flower strips to enhance the control of target pests (Tschumi et al. 2016a). It is also important to attract predators close to greenhouses early on in the growing season of eggplants, so as to avoid an exponential growth of the pest population (Jaworski et al. 2019). In light of this, borage, cosmos and cornflower have peak flowering times coinciding with times of rapid population growth of aphids in greenhouses (Figs. 2, 5). Thistle and verbena flower earlier and might be unattractive anymore when predators are most needed for biological control, although such flowering species may still be important to retain predators close to greenhouses and help build up predator populations early in the season for efficient biological control once pest populations emerge.

Combining multiple flowering species in a mixture in flower strips would allow a combination of their functional traits (e.g., color and scent, corolla depth, flowering peak) to attract a diversity of predator guilds (Campbell et al. 2012; Hatt et al. 2017b, 2018a, b; Fiedler and Landis 2007). For instance, mixing the flowering species tested here would provide flowers continuously from the end of early June to late July (Fig. 2). Mixing flowering species would also dilute the abundance of host plants suitable for pests and potentially reduce their ability to colonize greenhouses (resource concentration hypothesis, Root 1973). The potential for flower mixtures in flower strips to enhance pest control inside greenhouses by attracting and supporting high predator populations and low pest populations should be further tested in commercial organically grown greenhouse farms.

We showed that flower strips enhance pest regulation inside adjacent greenhouses by attracting predators of aphids, despite also attracting aphids, compared with weedy strips. This movement of natural enemies from surrounding habitat to flower strips and finally to greenhouses likely occurs via the greenhouses' ventilation systems. While there is no a priori reason to think that their movement might be influenced by the crop plants' spatial distribution inside greenhouses, it is likely to be influenced by the spatial arrangement of flower strips (one vs. two sides of each greenhouse, every other greenhouse, etc.). This deserves further investigation, as a way to improve pest management (Jaworski et al. 2019). The peri-urban context of the present experiment suggests that managing non-crop habitats at the local scale in farms can help reduce insecticide dependency in crop fields while meeting global food demand.

\section{Author contributions}

FZ, ND and SW conceived the research; SL collected the field data; CCJ, SH and SL performed the statistical analyses; SL, CCJ and SH prepared the manuscript; and all authors reviewed the manuscript before submission.

Acknowledgements This study was supported by funds from the National Key R\&D Program of China ( ref. 2017YFD0201000), the Technical Innovation Program of Beijing Academy of Agriculture and Forestry Sciences (ref. 20200110), the Youth Scientific Funds Program of BAAFS (ref. QNJJ201823), the Beijing NOVA Program (ref. Z121105002512039) and the EUCLID project (H2020-SFS-2014, ref. 633999). 


\section{Compliance with ethical standards}

Conflict of interests The authors declare no competing or financial interests.

\section{References}

Baggen L, Gurr G, Meats A (1999) Flowers in tri-trophic systems: mechanisms allowing selective exploitation by insect natural enemies for conservation biological control. Entomol Exp Appl 91:155-161

Balzan MV, Bocci G, Moonen AC (2016) Utilisation of plant functional diversity in wildflower strips for the delivery of multiple agroecosystem services. Entomol Exp Appl 158:304-319

Balzan MV, Wäckers FL (2013) Flowers to selectively enhance the fitness of a host-feeding parasitoid: adult feeding by Tuta absoluta and its parasitoid Necremnus artynes. Biol Control 67:21-31

Bates D, Maechler M, Bolker B, Walker S (2015) Fitting linear mixedeffects models using lme4. J Stat Softw 67:1-48

Berkvens N, Landuyt C, Deforce K, Berkvens D, Tirry L, Clercq PD (2010) Alternative foods for the multicoloured Asian lady beetle Harmonia axyridis (Coleoptera: Coccinellidae). Eur J Entomol 107:189-195

Bonte J, Hauwere LD, Conlong D, Clercq PD (2015) Predation capacity, development and reproduction of the southern African flower bugs Orius thripoborus and Orius naivashae (Hemiptera: Anthocoridae) on various prey. Biol Control 86:52-59

Bueno VHP, Silva AR, Carvalho LM, Moura N, Castañé C, Perdikis D (2009) Control of thrips with Orius insidiosus in greenhouse cut roses: use of a banker plant improves the performance of the predator. IOBC/WPRS Bulletin 49:183-187

Bugg RL, Waddington C (1994) Using cover crops to manage arthropod pests of orchards: a review. Agric Ecosyst Environ 50:11-28

Campbell AJ, Biesmeijer JC, Varma V, Wäckers FL (2012) Realising multiple ecosystem services based on the response of three beneficial insect groups to floral traits and trait diversity. Basic Appl Ecol 13:363-370

Campbell AJ, Wilby A, Sutton P, Wäckers F (2017) Getting more power from your flowers: multi-functional flower strips enhance pollinators and pest control agents in apple orchards. Insects 8:101

Carrié RJG, George DR, Wäckers FL (2012) Selection of floral resources to optimise conservation of agriculturally-functional insect groups. J Insect Conserv 16:635-640

Cui LL, Francis F, Heuskin S, Lognay G, Liu YJ, Dong J, Chen JL, Song XM, Liu Y (2012) The functional significance of E- $\beta$ Farnesene: does it influence the populations of aphid natural enemies in the fields? Biol Control 60:108-112

Dai P, Zhang X, Xiao C, Zhang X, Yu Z, Liu Y (2015) Habitat management and plant configuration for biological pest control in agricultural landscapes. Chinese J Eco-Agric 23:9-19

Damien M, Le Lann C, Desneux N, Alford L, Al Hassan D, Georges R, Baaren JV (2017) Flowering cover crops in winter increase pest control but not trophic link diversity. Agric Ecosyst Environ 247:418-425

Desneux N, Decourtye A, Delpuech JM (2007) The sublethal effects of pesticides on beneficial arthropods. Annu Rev Entomol 52:81-106

Dixon AFG, Kundu R (1994) Ecology of host alternation in aphids. Eur J Entomol 91:63-70

Fiedler AK, Landis DA (2007) Attractiveness of Michigan native plants to arthropod natural enemies and herbivores. Environ Entomol 36:751-765

Gabarra R, Alomar O, Castane C, Goula M, Albajes R (2004) Movement of greenhouse whitefly and its predators between in- and outside of Mediterranean greenhouses. Agric Ecosyst Environ 102:341-348

Gao Y, Wu L (2017) Flower border plants selection guide. Huazhong University of Science \& Technology Press, Wuhan, pp 72-102.

Geiger F, Bengtsson J, Berendse F et al (2010) Persistent negative effects of pesticides on biodiversity and biological control potential on European farmland. Basic Appl Ecol 11:97-105

Gontijo LM, Beers EH, Snyder WE (2013) Flowers promote aphid suppression in apple orchards. Biol Control 66:8-15

González-Chang M, Tiwari S, Sharma S, Wratten SD (2019) Habitat management for pest management: limitations and prospects. Ann Entomol Soc Am 112:302-317

Gurr GM, Lu Z, Zheng X, Xu H, Zhu P, Chen G, Yao X, Cheng J, Zhu Z, Catindig JL (2016) Multi-country evidence that crop diversification promotes ecological intensification of agriculture. Nature Plants 2:16014

Gurr GM, Wratten SD, Landis DA, You M (2017) Habitat management to suppress pest populations: progress and prospects. Annu Rev Entomol 62:91-109

Haro MM, Silveira LCP, Wilby A (2018) Stability lies in flowers: plant diversification mediating shifts in arthropod food webs. PLoS ONE 13:e0193045

Hartig F (2019) DHARMa: Residual Diagnostics for Hierarchical (Multi-Level/Mixed) Regression Models. R package version 0.2.4. https://CRAN.R-project.org/package $=$ DHARMa

Hatt S, Boerave F, Artru S, Dufrêne M, Francis F (2018a) Spatial diversification of agroecosystems to enhance biological control and other regulating services: an agroecological perspective. Sci Total Environ 621:600-611

Hatt S, Francis F, Xu Q, Wang S, Osawa N (2020) Perennial flowering strips for conservation biological control of insect pests: from picking and mixing flowers to tailored functional diversity. In: Gao Y, Hokkanen HMT, Menzler-Hokkanen I (eds) Integrative biological control. Springer, Cham, Switzerland, pp 57-71

Hatt S, Lopes T, Boeraeve F, Chen J, Francis F (2017a) Pest regulation and support of natural enemies in agriculture: experimental evidence of within field wildflower strips. Ecol Eng 98:240-245

Hatt S, Uyttenbroeck R, Lopes T, Chen JL, Piqueray J, Monty A, Francis F (2018b) Effect of flower traits and hosts on the abundance of parasitoids in perennial multiple species wildflower strips sown within oilseed rape (Brassica napus) crops. Arthropod-Plant Interactions 2:787-797

Hatt S, Uyttenbroeck R, Lopes T, Mouchon P, Chen J, Piqueray J, Monty A, Francis F (2017b) Do flower mixtures with high functional diversity enhance aphid predators in wildflower strips? Eur J Entomol 114:66-76

Hatt S, Uytenbroeck R, Lopes T, Mouchon P, Osawa N, Piqueray J, Monty A, Francis F (2019a) Identification of flower functional traits affecting abundance of generalist predators in perennial multiple species wildflower strips. Arthropod-Plant Interactions 13:127-137

Hatt S, Xu Q, Francis F, Osawa N (2019b) Aromatic plants of East Asia to enhance natural enemies towards biological control of insect pests. A review Entomol Gen 38:275-315

Hogg BN, Bugg RL, Daane KM (2011) Attractiveness of common insectary and harvestable floral resources to beneficial insects. Biol Control 56:76-84

Holland JM, Bianchi FJ, Entling MH, Moonen AC, Smith BM, Jeanneret $P$ (2016) Structure, function and management of seminatural habitats for conservation biological control: a review of European studies. Pest Manag Sci 72:1638-1651

Hothorn T, Bretz F, Westfall P (2008) Simultaneous inference in general parametric models. Biometrical J 50:346-363

Jaworski CC, Xiao D, Xu Q, Ramirez-Romero R, Guo X, Wang $S$, Desneux N (2019) Varying the spatial arrangement of synthetic herbivore-induced plant volatiles and companion 
plants to improve conservation biological control. J Appl Ecol $56: 1176-1188$

Ji S (2007) Study on the application and species resource of flower border plant in Beijing. J Beijing Garden 3:20-23

Karin W, Felix W, Deliam P (2009) Nectar-providing plants enhance the energetic state of herbivores as well as their parasitoids under field conditions. Ecol Entomol 34:221-227

Kogan M (1998) Integrated pest management: historical perspectives and contemporary developments. Annu Rev Entomol 43:243-270

Lu YH, Wu KM, Jiang YY, Guo YY, Desneux N (2012) Widespread adoption of Bt cotton and insecticide decrease promotes biocontrol services. Nature 487:362-365

Lu ZX, Zhu PY, Gurr GM, Zheng XS, Read DM, Heong KL, Yang YJ, Xu HX (2014) Mechanisms for flowering plants to benefit arthropod natural enemies of insect pests: prospects for enhanced use in agriculture. Insect Sci 21:1-12

Lundgren JG, Wyckhuys KAG, Desneux N (2009) Population responses by Orius insidiosus to vegetational diversity. Biocontrol 54:135-142

Michaud J (2018) Challenges to conservation biological control on the High Plains: 150 years of evolutionary rescue. Biol Control 125:65-73

Mohammed AAH, Desneux N, Fan YJ, Han P, Ali A, Song DL, Gao XW (2018) Impact of imidacloprid and natural enemies on cereal aphids: integration or ecosystem service disruption? Entomol Gen 37:47-61

Nakano R, Tsuchida Y, Doi M, Ishikawa R, Tatara A, Amano Y, Muramatsu Y (2016) Control of Bemisia tabaci (Gennadius) on tomato in greenhouses by a combination of Nesidiocoris tenuis (Reuter) and banker plants. Ann Rept Kansai PI Prot 58:65-72.

Oksanen J, Blanchet GF, Friendly M, Kindt R, Legendre P, McGlinn D, Minchin PR, O'Hara RB, Simpson GL, Solymos P, Stevens MHH, Szoecs E, Wagner H (2019) vegan: Community Ecology Package. R package version 2.5-6. https://CRAN.R-project.org/ package $=$ vegan.

Orr D (2009) Biological control and integrated pest management. In: Peshin R, Dhawan AK (eds) Integrated pest management: innovation-development process, vol 1. Springer, Netherlands, pp 207-239

Parolin P, Bresch C, Poncet C, Desneux N (2012) Functional characteristics of secondary plants for increased pest management. Int $\mathrm{J}$ Pest Manag 58:369-377

Perović DJ, Gámez-Virués S, Landis DA et al (2018) Managing biological control services through multi-trophic trait interactions: review and guidelines for implementation at local and landscape scales. Biol Rev 93:306-321

Pfiffner L, Luka H, Schlatter C, Juen A, Traugott M (2009) Impact of wildflower strips on biological control of cabbage Lepidopterans. Agric Ecosyst Environ 129:310-314

Pretty J (2018) Intensification for redesigned and sustainable agricultural systems. Science 362: eaav0294.

R Core Team (2019) R: A language and environment for statistical computing. R Foundation for Statistical Computing, Vienna, Austria, https://www.R-project.org/.

van Rijn PCJ, Wäckers FL (2016) Nectar accessibility determines fitness, flower choice and abundance of hoverflies that provide natural pest control. J Appl Ecol 53:925-933

Rodríguez E, González M, Paredes D, Campos M, Benítez E (2017) Selecting native perennial plants for ecological intensification in Mediterranean greenhouse horticulture. Bull Entomol Res 108:694-704
Root RB (1973) Organization of a plant-arthropod association in simple and diverse habitats: the fauna of collards (Brassica oleracea). Ecol Monog 43:95-124

Rusch A, Chaplin-Kramer R, Gardiner MM, Hawro V, Holland J et al (2016) Agricultural landscape simplification reduces natural pest control: a quantitative synthesis. Agric Ecosyst Environ 221:198-204

Sadeghi H (2008) Abundance of adult hoverflies (Diptera: Syrphidae) on different flowering plants. Caspian J Environ Sci 6:47-51

Sarkar S, Wang E, Wu S, Lei Z (2018) Application of trap cropping as companion plants for the management of agricultural pests: a review. Insects 9:128

Snyder WE (2019) Give predators a complement: Conserving natural enemy biodiversity to improve biocontrol. Biol Control 135:73-82

Song B, Tang G, Sang X, Zhang J, Yao Y, Wiggins N (2013) Intercropping with aromatic plants hindered the occurrence of Aphis citricola in an apple orchard system by shifting predator-prey abundances. Biocontrol Sci Techn 23:381-395

Theis N (2006) Fragrance of Canada thistle (Cirsium arvense) attracts both floral herbivores and pollinators. J Chem Ecol 32:917

Thomine E, Rusch A, Supplisson C, Monticelli LS, Amiens-Desneux E, Lavoir AV, Desneux N (2020) Highly diversified crop systems can promote the dispersal and foraging activity of the generalist predator Harmonia axyridis. Entomol Gen. https://doi. org/10.1127/entomologia/2020/0894

Tscharntke T, Bommarco R, Clough Y, Crist TO, Kleijn D, Rand TA, Tylianakis JM, van Nouhuys S, Vidal S (2007) Conservation biological control and enemy diversity on a landscape scale. Biol Control 43:294-309

Tschumi M, Albrecht M, Bärtschi C, Collatz J, Entling MH, Jacot K (2016a) Perennial, species-rich wildflower strips enhance pest control and crop yield. Agric Ecosyst Environ 220:97-103

Wäckers FL, van Rijn PC (2012) Pick and mix: selecting flowering plants to meet the requirements of target biological control insects. In: Gurr GM, Wratten SD, Snyder WE, Read, DMY (eds) Biodiversity and insect pests: key issues for sustainable management; 1st edn. Wiley, New York, pp 139-165.

Tschumi M, Albrecht M, Collatz J, Dubsky V, Entling MH, NajarRodriguez AJ, Jacot K (2016b) Tailored flower strips promote natural enemy biodiversity and pest control in potato crops. J Appl Ecol 53:1169-1176

Wang S, Michaud JP, Tan XL, Zhang F (2014) Comparative suitability of aphids, thrips and mites as prey for the flower bug Orius sauteri (Hemiptera: Anthocoridae). Eur J Entomol 111:221-226

Winkler K, Wäckers FL, Kaufman LV, Larraz V, Lenteren JCV (2009) Nectar exploitation by herbivores and their parasitoids is a function of flower species and relative humidity. Biol Control 50:299-306

Yang NW, Zang LS, Wang S, Guo JY, Xu HX, Zhang F, Wan FH (2014) Biological pest management by predators and parasitoids in the greenhouse vegetables in China. Biol Control 68:92-102

Zhang B (2012) Investigation on the application of herbaceous flowers in urban park green space of Beijing. J Anhui Agric 40:8580-8583

Publisher's Note Springer Nature remains neutral with regard to jurisdictional claims in published maps and institutional affiliations. 